\title{
Calibration of a desktop scanner and digital image analysis procedure for quantification of root morphology
}

\author{
Asko Simojoki \\ Department of Applied Chemistry and Microbiology, PO Box 27, FIN-00014 University of Helsinki, Finland, \\ e-mail:asko.simojoki@helsinki.fi
}

\begin{abstract}
Methodological tests with dark metal wires and barley roots showed that selecting proper scanner brightness adjustment is crucial when calibrating a desktop scanner for digital image analysis of root morphology. At high brightness the digitization of roots was incomplete, and thus the real length and width of the roots were underestimated. Lowering of the brightness improved the digitization, whereas stronger staining of the roots alone was not effective. Inaccurate results were produced also, if the size of the scanned sample was too large. The variation caused by the scanning and image analysis itself was minimal. A small amount of dry matter was lost from the roots during the preservation in the ethanol solution for several months before scanning. If absolute data on root masses are required, this loss cannot be neglected. Subsampling is strongly recommended to reduce the time required for the procedure.
\end{abstract}

Key words: barley, length, sampling, surface area, staining, volume, width

\section{Introduction}

Digital image analysis of washed roots permits comprehensive examination of root length, diameter and surface area (Zoon and van Tiederen 1990, Ewing and Kaspar 1995, Tanaka et al. 1995, Pietola and Smucker 1998). In recent years the use of high-quality desktop scanners in root studies has become a practical tool that overcomes the limitations of other image analysis procedures such as inadequate imaging resolution and the requirement for random orientation of the sample (Pan and Bolton 1991). Scanners, like any measurement instruments, have to be calibrated to give accurate data. The calibration depends in general on the properties of the scanning system and roots and on the method of image analysis. The reliability of results may be impaired e.g. by an inappropriate brightness adjustment of the scanner and a too large sample size. Although these issues have been addressed to some extent in previous studies, there is not much quantitative information available about them, especially in analysis of roots having diameters less than $0.3 \mathrm{~mm}$. This study was car- 


\section{Simojoki, A. Image analysis of root morphology}

ried out to quantify the impact of these factors on the measurements of fine roots. The paper reports several important precautions and tests that are useful when calibrating a desktop scanner for image analysis of root morphology.

\section{Material and methods}

The accuracy and precision of an image analysis method was assessed using pieces of dark metal wires and stained barley roots (Hordeum vulgare L. cv. Kymppi). The root samples were taken from a series of pot experiments with various treatments of compaction, wetting and aeration of soil (Simojoki et al., unpublished). Before the actual image analysis, the roots were cleaned, stained, placed on a glass tray on the scanner, and digitized. The techniques of the pretreatment and image analysis of the root samples were taken and partly modified from those published earlier (Smucker et al. 1982, Kaspar and Ewing 1997, Pietola and Smucker 1998).

Mineral soil (c. $0.45 \mathrm{dm}^{3}$ per sample) was separated from the roots by a hydropneumatic elutriation system equipped with $930-\mu \mathrm{m}$ screens (Smucker et al. 1982), and the remaining organic debris was removed manually with tweezers. After the cleaning and the removal of excess water by vacuum filtration, the samples were weighed moist. Half of each sample (by mass) was stored at $+4^{\circ} \mathrm{C}$ in $50 \mathrm{ml}$ volume of $15 \%$ ethanol solution for later scanning, whereas the other half was used for the determination of dry matter content.

Before scanning, the roots were stained for at least two days by adding $5 \mathrm{ml} \mathrm{g}^{-1}$ of malachite green (oxalate) solution $\left(10 \mathrm{mg} \mathrm{ml}^{-1}\right.$ in $15 \%$ ethanol) according to the estimated dry mass of the root sample (Pietola and Smucker 1998). Extra stain was removed from the roots by flushing them with water on a nylon filter. To facilitate scanning, the roots were cut into $1-2 \mathrm{~cm}$ pieces and spread evenly, avoiding overlapping, on a glass tray $(18.8 \mathrm{~cm} \times 28.5 \mathrm{~cm})$ covered with 2 $\mathrm{mm}$ of water. Very often the samples were so large they had to be scanned in sections. From the largest samples only a subsample (about $15 \%$ ) was scanned. Subsampling was carried out by placing the roots uniformly on the tray and taking a sample from the middle of the tray.

Roots were scanned at a resolution of 600 dpi (dots per inch) (23.6 pixels $\mathrm{mm}^{-1}$ ) by a flatbed scanner (HP DeskScan II 4c) equipped with a transparency adapter. The digitized black and white line art images were saved in the TIFFformat. They were analysed for root length and width by the ROOTEDGE image analysis program (Kaspar and Ewing 1997) using a closing operation with a test coefficient of 2 in 8-connected space (T. Kaspar and T. Ewing, personal communication in 1997). Objects smaller than $0.1 \mathrm{~mm}^{2}$ and with a length/width ratio smaller than 2 were excluded from the image analysis. Assuming that the roots were cylindrical, the average root width was calculated by dividing the projection area of roots by their length.

The dry mass of scanned roots was determined after drying the roots in an oven at $70^{\circ} \mathrm{C}$ for $48 \mathrm{~h}$ and after another $48 \mathrm{~h}$ at $105^{\circ} \mathrm{C}$. The specific length of the roots was calculated by dividing the length of the roots by their mass. The dry matter lost from the roots during the preservation in the ethanol solution was estimated by comparing the dry mass of roots measured after scanning to that calculated from the moist mass of the sample before the preservation and the dry matter content of the non-scanned half of the sample.

The scanner brightness adjustment is an exposure control that determines the threshold shade of gray that is designated as black in the images scanned as black and white line art images. The numerical values of the brightness adjustment in the scanner program ranged from 1 to 250 . The accuracy of the image analysis method was assessed by comparing the results at various levels of scanner brightness (in a range of 30-130) to each other and to the manual measurements. The lengths and widths of individual objects were measured manually with a sliding gauge and with a micrometer, respectively. The 
Vol. 9 (2000): 223-230.
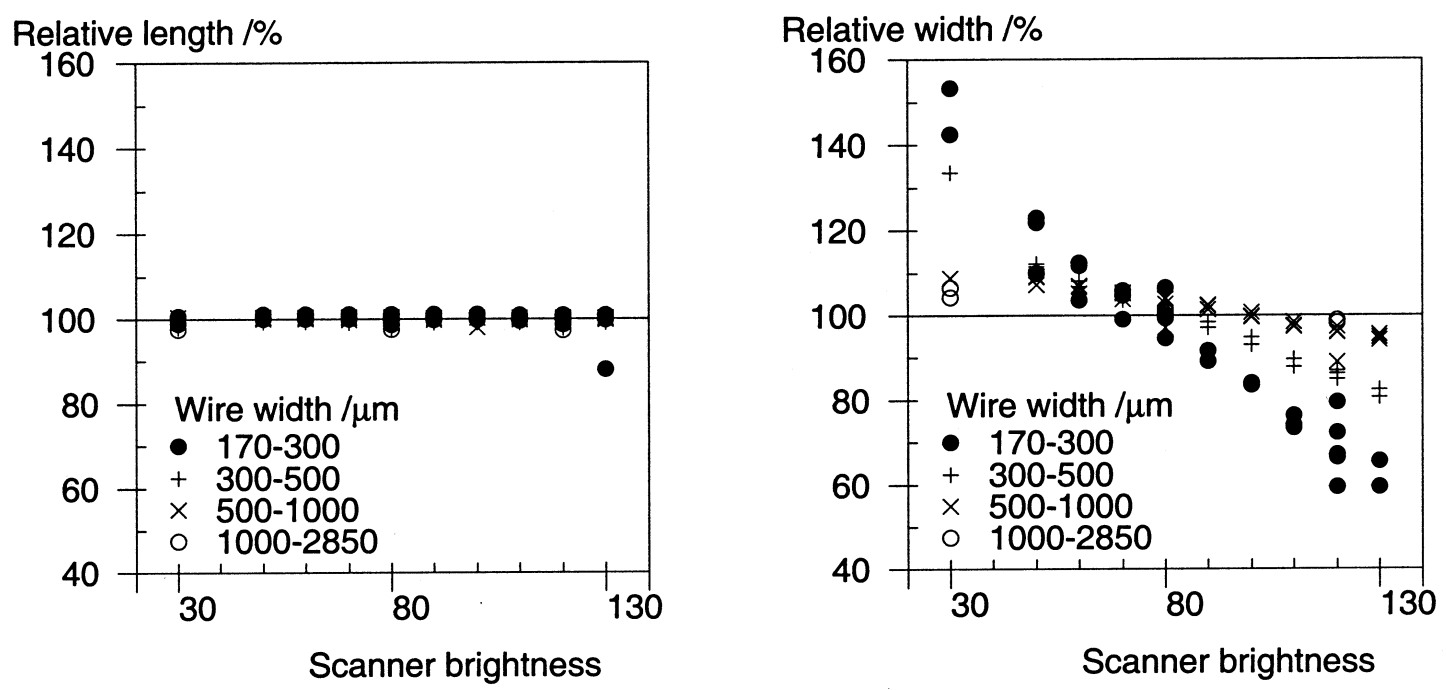

Fig. 1. The relative length and width of $1.0-5.0 \mathrm{~cm}$ metal wires of various thickness measured by analysing the images scanned at various brightness adjustments $(100 \%=$ manual measurement of length with a sliding gauge or that of width with a micrometer gauge).

effect of sample size on the results was examined by splitting large samples into sections, and by comparing the result obtained by scanning the whole sample at a time to that obtained as a sum of the sections.

\section{Results and discussion}

Tests with dark metal wires of known length and width showed that proper brightness adjustment in scanning is critical in order to obtain accurate results (Fig. 1). The lengths of metal wires were measured quite accurately by image analysis, while their widths were overestimated at low brightness and underestimated at high brightness. Based on these measurements a brightness adjustment value of 80 was first chosen to be used routinely for scanning the roots. When the scanned images of root samples were later examined by eye, it was noticed that staining obviously did not make the roots opaque, as at high brightness the roots were not completely digi- tized. Tests with six root samples showed that extra staining of the roots with four-fold the usual amount of dye did not effectively improve digitization, but lowering the brightness did (Fig. 2). In fact, the results suggested that the digitization of normally stained roots was still incomplete even at the low brightness (30), as the extra staining of roots increased the estimated root length on average by $6 \%$. The estimated root width was however not affected. The stronger staining of roots was not possible in practice due to the long time required for removing the excess dye from the roots and the risk of leakage of the dye on the tray. On the other hand, the brightness adjustment could not be lowered below 30 due to the risk for false recognition of background pixels as objects pixels. Thus, the remaining root samples were stained as usual and scanned at both low (30) and high (80) brightness.

Root length obtained at low brightness was usually about two-fold that obtained at high brightness, whereas the estimates for root width differed only by $20-30 \%$ (Fig. 3). Linear correlation between the estimates was much higher 
Simojoki, A. Image analysis of root morphology
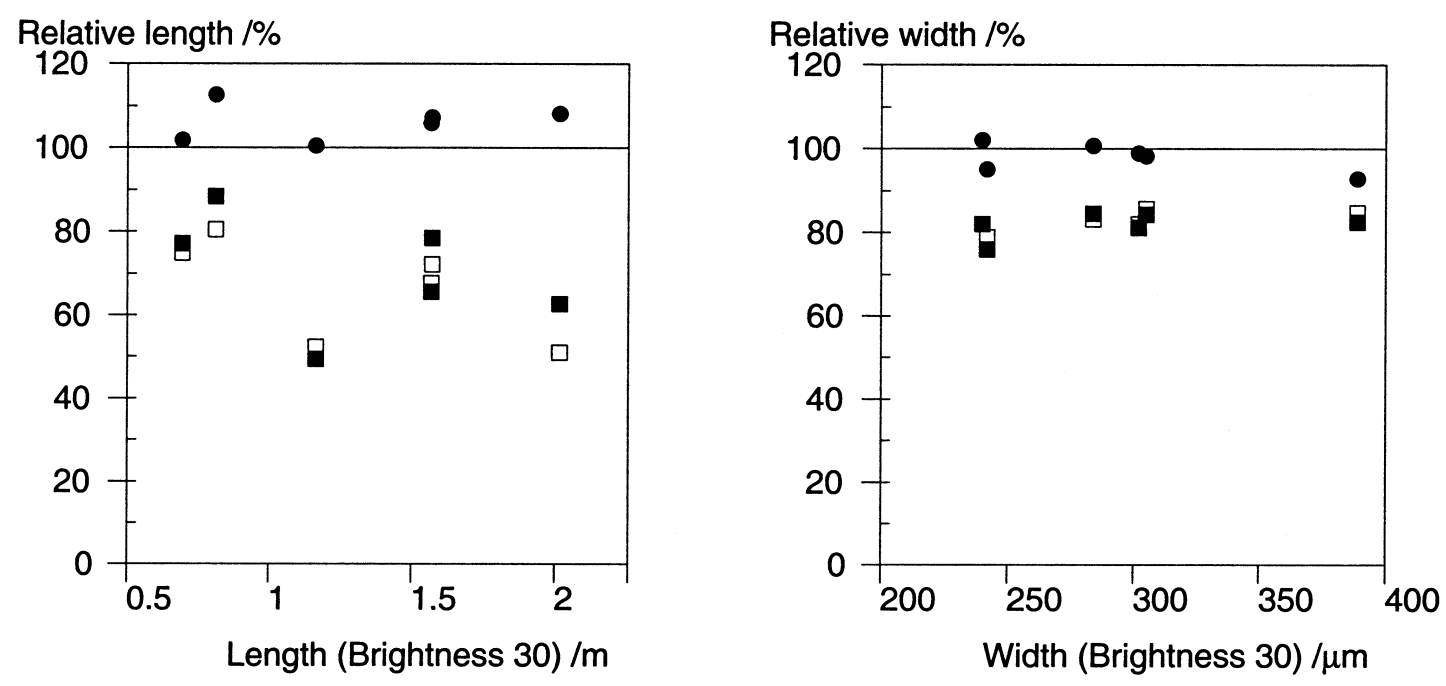

Fig. 2. The effect of scanner brightness and staining of roots on the relative length and width of roots in six root samples $(100 \%=$ the result measured at brightness adjustment value 30$)$. Symbols: open: normal staining, closed: extra staining with four-fold amount of dye, square: brightness 80 , circle: brightness 30 .

for root width $(\mathrm{r}=0.94, \mathrm{P}<0.001, \mathrm{n}=71)$ than that for root length $(\mathrm{r}=0.48, \mathrm{P}<0.001, \mathrm{n}=71)$. The improved acquisition of the scanned image at low brightness agrees with the results of Kaspar and Ewing (1997).

SRL (Brightness 30) $/ \mathrm{m} \mathrm{g}^{-1}$

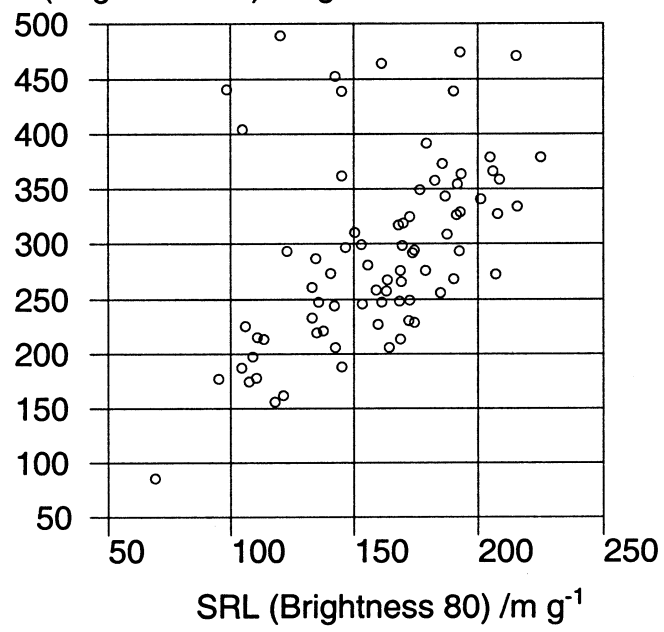

The width of the thinnest metal wires (170$300 \mu \mathrm{m}$ ) was overestimated by more than $50 \%$, as the wires in the images scanned at the low brightness were by $97 \pm 15 \mu \mathrm{m}$ (mean difference \pm standard deviation, $n=6$ ) thicker than in real-

RW (Brightness 30) / $\mu \mathrm{m}$

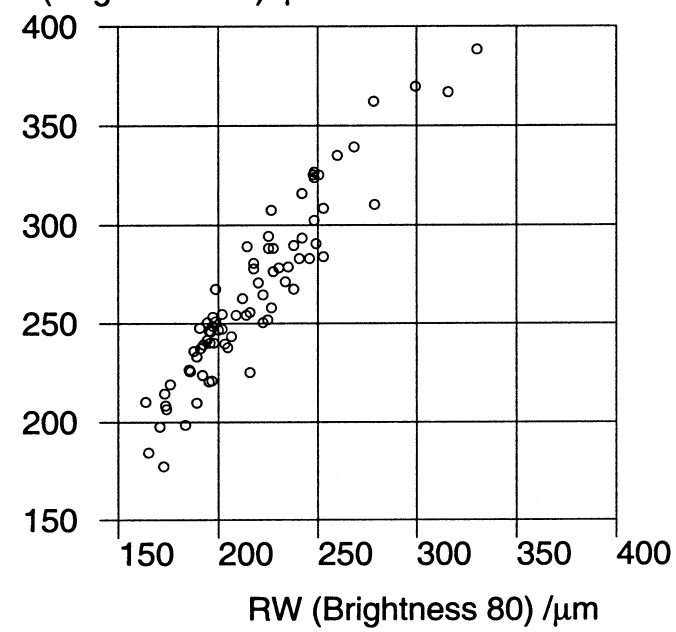

Fig. 3. Specific root length (SRL) and root width (RW) measured by analysing the images scanned at low (30) and high (80) brightness adjustments. 
Vol. 9 (2000): 223-230.
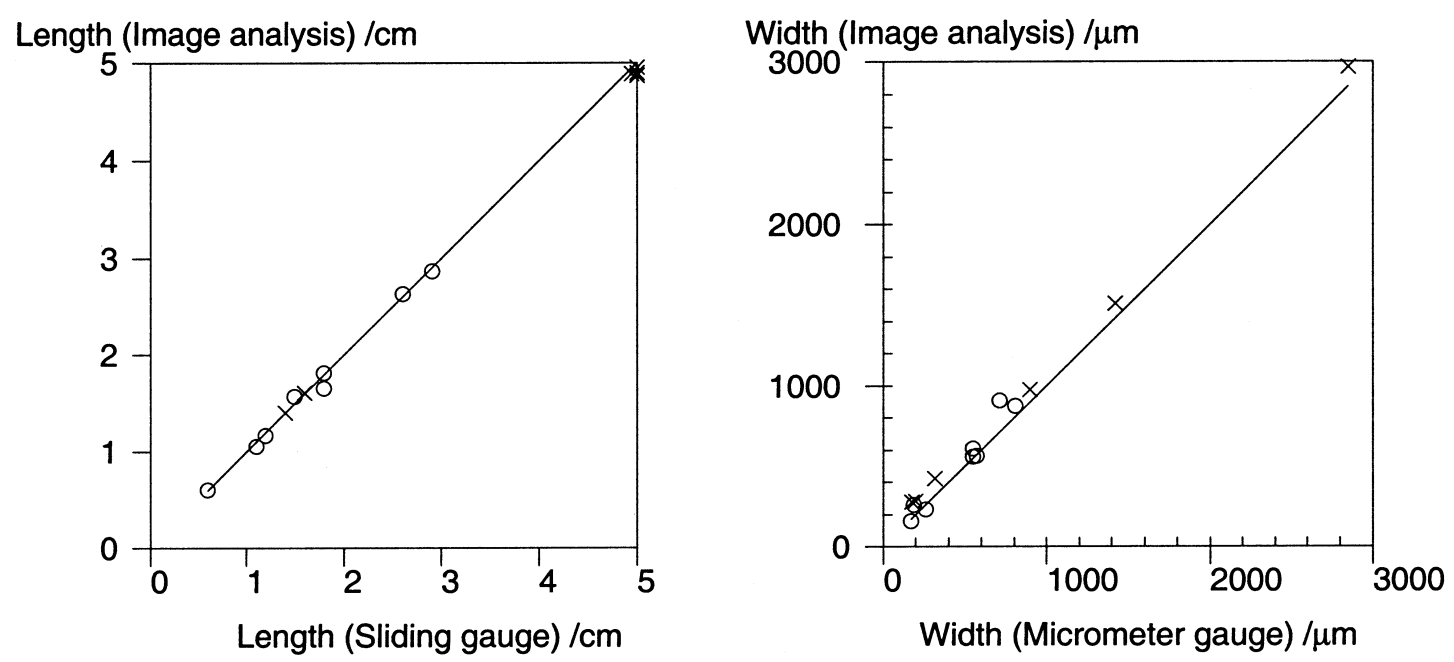

Fig. 4. Length and width of metal wires $(\times)$ and roots $(\bigcirc)$ measured manually and by analysing the images scanned at low brightness (30) (lines 1:1). Root width was measured manually with the micrometer of a microscope.

ity (Figs. 1 and 4). Root width could have been similarly overestimated, if staining had made the roots opaque. The length and width of individual root pieces $(n=8)$ were however usually close to those measured manually (Fig. 4).

When large samples were scanned, it was not possible to avoid overlapping of the roots. Tests were made with barley roots to find out how large a sample could be scanned on one tray and how sensitive the results were to overlapping roots (Fig. 5). Although the total projection area of roots even in the largest samples remained approximately the same irrespective of whether the whole sample was scanned at a time or in many sections, the estimate for root length decreased and that for root width increased as root length on the tray increased.

The results indicate that about $2 \mathrm{~m}$ of barley roots can be placed on a $535 \mathrm{~cm}^{2}$ tray $(0.4 \mathrm{~cm}$ $\mathrm{cm}^{-2}$ ) at a time without much effect on the estimated root length. Scanning $15 \mathrm{~m}$ of roots at a time lowered the estimate of root length by $25 \%$ and increased that of root width by $35 \%$. Assuming a specific root length of $300 \mathrm{~m} \mathrm{~g}^{-1}$ these root lengths correspond to $7 \mathrm{mg}$ and $50 \mathrm{mg}$ root dry matter, respectively.
The results produced by the image analysis method were highly reproducible. When the same root sample was scanned five times the coefficient of variation for the root width was $0.2 \%$ and that for root length $0.4 \%$, and replacing the sample repeatedly on the tray increased the coefficients of variation not more than four-

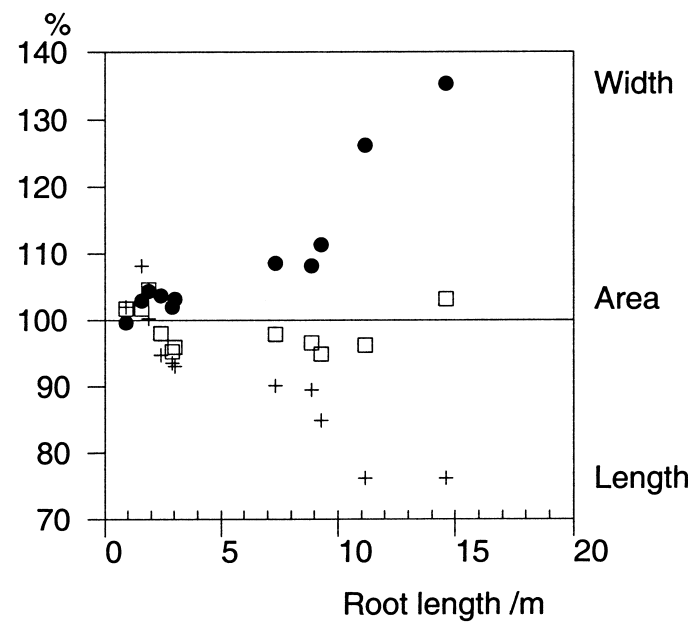

Fig. 5. The effect of scanned sample size on the relative width, projection area and length of roots $(100 \%=$ result of the sample scanned in sections). 
Simojoki, A. Image analysis of root morphology

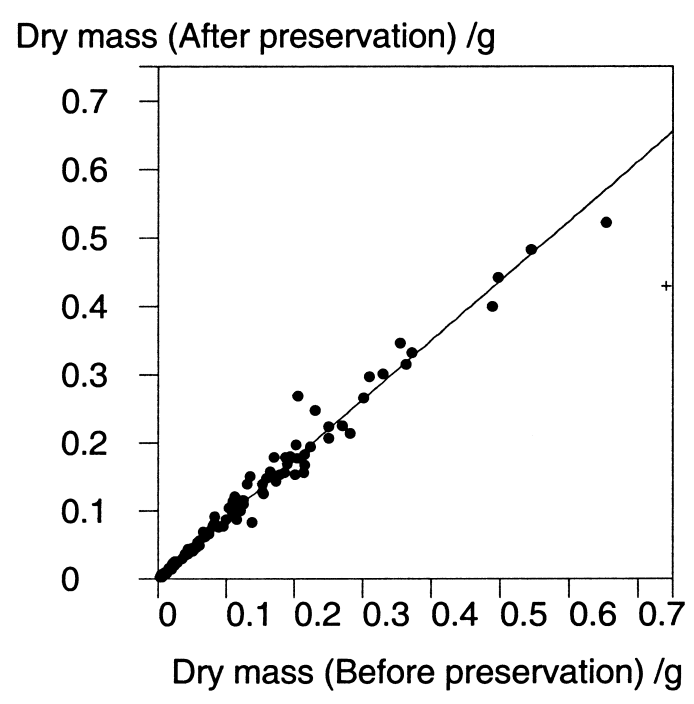

Fig. 6. Dry mass of root samples before and after preservation in ethanol solution (an outlier is denoted with + ).

fold. The reproducibility is roughly similar to that reported by Kaspar and Ewing (1997) for root length determination.

Despite the general agreement that the roots are preserved satisfactorily in 15-20\% alcohol solutions (Böhm 1979, Smucker 1990), no data on the magnitude of the possible loss seem to have been published. In the present study, the root samples lost about $13 \%$ of their dry mass during the 3-10 months of preservation in the ethanol solution (Fig. 6). It is unknown how much the decay changed the root morphology, but it may be safely assumed that the effect on the biomass of roots was larger than that on their lengths and widths, and thus the specific length of roots was probably slightly overestimated. In contrast, the choice of drying temperature was not critical for the dry mass determination of roots, as the dry mass after $48 \mathrm{~h}$ at $70^{\circ} \mathrm{C}$ was only $1 \%$ higher than that after an extra $48 \mathrm{~h}$ at $105^{\circ} \mathrm{C}$. However, for roots much thicker than the barley roots in this study, such as carrot tap roots, the difference can be much larger (Pietola 1995).

The image analysis of roots consists of many procedures. This may in itself impair the quality of the results, as each procedure involves a source of variation and a risk of misfortune. The cleaning of washed roots from organic debris is usually the most laborious and time-consuming step. Depending on the amounts of roots and organic debris involved, and the fragmentation of the roots, the rate of cleaning may vary from several samples per day to several days per sample. Nevertheless, the cleaning of roots is unavoidable in studies like the present one, where the proportion of roots was, on average, only about $10 \%$ of the total mass of roots and debris in the sample. The amount of debris in the cleaned samples was insignificant: the share of small or round objects that were normally excluded from the image analysis corresponded to only $4 \%$ of the projection area of all objects. The scanning and image analysis in itself is rapid, but due to the time needed for placing the roots on the scanner tray only 10-20 images can easily be acquired in one day.

In the present study, all the roots in the sample were cleaned. The time required for the analysis was reduced by scanning only a subsample of the largest samples. In the later studies in our root laboratory, we have however reduced the time requirements still further by cleaning only subsamples of the original sample. The total length, surface area and volume of roots in the original sample are then calculated based on the root morphological properties and the amounts of organic debris and roots estimated in the subsample, and on the proportion of the subsample.

Cutting of the root samples into pieces before scanning has many advantages. It allows the roots to be placed easily on the tray in a random fashion and without overlapping. It also facilitates easier and representative subsampling of the roots. Moreover, if either hardware or software were sensitive to object orientation, the random orientation of objects would probably improve the quality of results. In this study, the effect was probably insignificant, as the algorithm of the image analysis program is not sensitive to object orientation (Ewing and Kaspar 1995) and as the scanner has the same optical resolution in both the horizontal and vertical di- 
Vol. 9 (2000): 223-230.

rections. Also the assumption of the image analysis program that the objects are rectangular is more realistic, if the roots are cut into pieces before scanning. This leads to more precise information about the root diameter distribution. A possible drawback of cutting is that information about the branching pattern of roots is lost.

To sum up, the methodological tests showed that selecting proper scanner brightness adjustment for digitization is critical for obtaining accurate results about root width and length by digital image analysis. In general, low brightness adjustment is recommended, but the selection should be suited to the method used for staining the roots. Inaccurate results are produced also, if the size of the scanned sample is too large. The variation caused by the scanning and the analysis itself is minimal. Some dry matter may be lost from roots during their preservation in the ethanol solution before scanning. Although this loss is rather small, it cannot be neglected, if absolute data on root masses are required. Subsampling is strongly recommended to reduce the time required for the procedure.

Acknowledgements. I thank Liisa Pietola for help and advice during the study, and Toby Ewing and Thomas Kaspar (National Soil Tilth Laboratory, Iowa, USA) for providing the ROOTEDGE program. I am grateful to Susanna Hyvärinen, Marjatta Koivisto, Eeva Kontkanen, Astrid Kovaljeff, Heli Kyrönkari, Riikka Simojoki, Timo Simojoki, Minna Smeds, Gerd Tötterman, and Riitta Viitala for technical support in the washing and analysis of roots, and Donald Smart for the English language revision. Financial support from the Academy of Finland is gratefully acknowledged.

\section{References}

Böhm, W. 1979. Methods of studying root systems. Berlin: Springer-Verlag. 188 p.

Ewing, R.P. \& Kaspar, T.C. 1995. Accurate perimeter and length measurement using an edge chord algorithm. Journal Computer Assisted Microscopy 7: 91-100.

Kaspar, T.C. \& Ewing, R.P. 1997. ROOTEDGE: Software for measuring root length from desktop scanner images. Agronomy Journal 89: 932-940.

Pan, W.L. \& Bolton, R.P. 1991. Root quantification by edge discrimination using a desktop scanner. Agronomy Journal 83: 1047-1052.

Pietola, L. 1995. Effect of soil compactness on the growth and quality of carrot. Agricultural and Food Science in Finland 4: 139-237.

- \& Smucker, A.J.M. 1998. Fibrous carrot root responses to irrigation and compaction of sandy and organic soils. Plant and Soil 200: 95-105.

Smucker, A.J.M. 1990. Quantification of root dynamics in agroecological systems. Remote Sensing Systems 5: 237-248.

-, McBurney, S.L. \& Srivastava, A.K. 1982. Quantitative separation of roots from compacted soil profiles by the hydropneumatic elutriation system. Agronomy Journal 74: 500-503.

Tanaka, S., Yamauchi, A. \& Kono, Y. 1995. Easily accessible method for root length measurement using an image analysis system. Japanese Journal of Crop Science 64: 144-147.

Zoon, F.C. \& van Tiederen, P.H. 1990. A rapid quantitative measurement of root length and root branching by microcomputer image analysis. Plant and Soil 126: 301-308. 
Simojoki, A. Image analysis of root morphology

\title{
SELOSTUS
}

\section{Tasoskannerin ja digitaalisen kuva-analyysimenetelmän kalibrointi juurten morfologian kvantifioimiseksi}

\author{
Asko Simojoki \\ Helsingin yliopisto
}

Testit tummilla metallilangoilla ja ohran juurilla osoittivat, että oikea valotussäätö on ensiarvoisen tärkeä kalibroitaessa tasoskanneria juurten morfologisten ominaisuuksien digitaalista kuva-analyysia varten. Jos valotus oli liian kirkas, juurten digitoituminen oli epätäydellistä, minkä vuoksi kuva-analyysi antoi juurille todellista pienemmän pituuden ja leveyden. Valotuksen himmentäminen paransi digitoitumista, kun taas juurten värjääminen neljä kertaa tavallista suuremmalla värimäärällä ei sitä tehnyt. Tu- lokset olivat epätarkkoja myös, jos kerralla skannattiin liian suuri näyte. Itse skannaus ja kuva-analyysi aiheuttivat tuloksiin vain vähän vaihtelua. Hieman kuiva-ainetta hävisi juurista, kun niitä säilytettiin monen kuukauden ajan $15 \%$ etanoliliuoksessa ennen skannausta. Vaikka määrä oli pieni, sitä ei voi kuitenkaan jättää ottamatta huomioon, jos tarkka tieto juurten massasta on tarpeen. Osanäytteen ottoa suositellaan käytettäväksi lyhentämään analyysimenetelmän eri vaiheiden vaatimaa aikaa. 